\title{
ENERGY, ENTROPY AND EXERGY ANALYSES OF HYBRID NANOFLUID FLOW IN A TRAPEZOIDAL CHANNEL
}

Mutlu TEKİ**, Department of Medical Engineering, Faculty of Engineering, Karabük University, Turkey, mutlutekir@karabuk.edu.tr

(iD) https://orcid.org/ 0000-0003-2289-7034)

Mutlucan BAYAT, Department of Mechanical Engineering, Faculty of Engineering, Karabük University, Turkey, mutlucanbayat@karabuk.edu.tr

(iD) https://orcid.org/ 0000-0002-3604-1707)

Kamil ARSLAN, Department of Mechanical Engineering, Faculty of Engineering, Karabük University, Turkey, kamilarslan@karabuk.edu.tr

(iD) https://orcid.org/ 0000-0002-1216-6812)

Received: 24.03.2021, Accepted: 10.05.2021

*Corresponding author

Research Article DOI: $10.22531 /$ muglajsci.901966

\section{Abstract}

This study presents energy, entropy, and exergy analyses of $\mathrm{Al}_{2} \mathrm{O}_{3}-\mathrm{Cu}$ /water hybrid nanofluid flow in a trapezoidal crosssectioned channel under a turbulent regime $\left(10^{4}<R e<10^{5}\right)$ for the first time. Understanding the main source of the entropy generation along the channel, also obtaining the total entropy variation of hybrid nanofluid comparing to single nanofluids $\left(\mathrm{Al}_{2} \mathrm{O}_{3} /\right.$ water and $\mathrm{Cu} /$ water) and base fluid is pursued objective. In other to perform these aforementioned analyses, a realistic model, in which all formulas are derived, is developed and thermodynamic concepts such as exergy efficiency and exergy destruction for hybrid nanofluid flow in a non-circular cross-sectioned channel are discussed for the first time. Results obtaining from the analyses of both hybrid and single nanofluids have been compared and discussed for volumetric concentrations of $1.0 \%$ and $2.0 \%$. As a result, it is obtained that $2.0 \%$ volume concentration hybrid nanofluid offers the best convective heat transfer performance with $34 \%$ enhancement and best exergetic performance. Furthermore, hybrid nanofluid has the lowest entropy generation value.

Keywords: Hybrid Nanofluid, CFD, Turbulent Flow, Convective Heat Transfer, Energy, Entropy, Exergy Analysis

\section{YAMUK KANAL İÇINDEKİ HIBBRİT NANOAKIŞKAN AKIŞININ ENERJİ, ENTROPİ VE EKSERJİ ANALIZİ}

\begin{abstract}
Özet
Bu çalışmada yamuk kesitli kanal içerisinde türbülanslı akış rejiminde $\left(10^{4}<\mathrm{Re}<10^{5}\right) \mathrm{Al}_{2} \mathrm{O}_{3}-\mathrm{Cu} / \mathrm{su}$ hibrit nanoakışkan akışı termodinamik açıdan ilk defa incelenmiştir. Kanal boyunca entropi üretiminin temel kaynağının anlaşılması, aynı

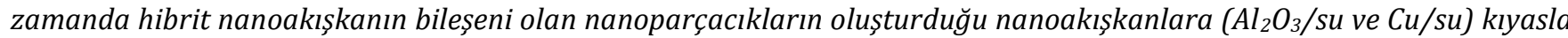
toplam entropi değişiminin elde edilmesi hedeflenmiştir. Bahsedilen bu analizlerin gerçekleştirilmesi için yamuk kesitli kanal için tüm formüller yeniden türetilerek gerçekçi bir model oluşturulmuş ve ekserji verimi ve ekserji yıkımı gibi termodinamik kavramlar, dairesel olmayan kesitli kanal içinde hibrit nanoakışkan akışı için ilk defa tartışılmıștır. Hibrit ve tek parçacıklı nanoakışkanların analizlerinden elde edilen sonuçlar, \%1,0 ve \%2,0 nanoparçacık hacimsel konsantrasyonlar için karşılaştırılmış ve tartışılmıştır. Sonuç olarak, \%2,0 hacimsel konsantrasyonunda hibrit nanoakışkanın tek parçacıklı nanoakışkanlara kıyasla \%34 artışla birlikte en yüksek taşınımla ısı transferi performansı ve ekserji performansı sunduğuna ulaşılmıştır. Ayrıca, hibrit nanoakışkanlar en düşük entropi üretim değerine sahiptirler.
\end{abstract}

Anahtar Kelimeler: Hibrit Nanoakıșkan, HAD, Türbülanslı Akış, Taşınımla Isı Transferi, Enerji, Entropi, Ekserji Analizi Cite

Tekir, M., Bayat, M., Arslan, K., (2021). “Energy, Entropy, and Exergy Analyses of Hybrid Nanofluid Flow in A Trapezoidal Channel", Mugla Journal of Science and Technology, 7(1), 106-116.

\section{Introduction}

Hybrid nanofluids are a new generation of nanofluids. Despite the detailed studies of the researchers on this type of nanofluids, a consistent and appropriate model concerning nanofluid properties and their instant behavior in the specific channels or tubes has not been proposed in most of the studies in literature. Takabi and Shokouhmand [1] studied $\mathrm{Al}_{2} \mathrm{O}_{3}-\mathrm{Cu}$ /water hybrid nanofluid with nanoparticle volume concentrations of 0 $2.0 \%$ in a circular tube under turbulent flow conditions. According to the study, Nusselt number and friction factor increased by $32.0 \%$ and $14.0 \%$, respectively with the use of hybrid nanofluid comparing to the base fluid. 
Besides, Selvakumar and Suresh [2] investigated experimentally $\mathrm{Al}_{2} \mathrm{O}_{3}-\mathrm{Cu}$ /water hybrid nanofluid in an electronic heat sink inside of a water block to enhance the cooling performance. With using $0.1 \%$ of hybrid nanofluid, the temperature difference decreased by $1{ }^{\circ} \mathrm{C}$ on average, and convective heat transfer increased by $24.0 \%$ according to distilled water. Furthermore, Suresh et al. [3] investigated experimentally $\mathrm{Al}_{2} \mathrm{O}_{3}-\mathrm{Cu}$ /water hybrid nanofluid under laminar flow conditions and it was found that Nusselt number increased $13.6 \%$ over the base fluid. In another study, also the production of $\mathrm{Al}_{2} \mathrm{O}_{3}-\mathrm{Cu}$ /water hybrid nanofluid was analyzed, and thermophysical properties of produced hybrid nanofluid were consequently discussed in detail [4]. Moreover, Moghadassi et al. [5] studied numerically $\mathrm{Al}_{2} \mathrm{O}_{3}-\mathrm{Cu}$ /water hybrid nanofluid in a tube under laminar flow conditions using a multiphase approach. Accordingly, using hybrid nanofluid provided an enhancement in Nusselt number by $13.5 \%$.

As examples for studies regarding entropy generation of nanofluids, Ahammed et al. [6] investigated experimentally $\mathrm{Al}_{2} \mathrm{O}_{3}$-graphene/water hybrid nanofluid and combinations of nanofluids under laminar flow condition in a horizontal tube. In this study, it was found that hybrid nanofluid presented $17.0 \%$ of heat transfer enhancement according to other tested combinations of hybrid nanofluid, whereas graphene/water nanofluid presented $88.0 \%$ of enhancement. Also, total entropy generation decreased by $32.0 \%$ with graphene/water nanofluid, and $20.0 \%$ with the hybrid nanofluid. Thus, graphene/water nanofluid presented the best heat transfer performance and exergetic characteristics. Moghaddami et al. [7] studied numerically entropy generations of $\mathrm{Al}_{2} \mathrm{O}_{3}$ /water and $\mathrm{Al}_{2} \mathrm{O}_{3}$ /ethylene glycol nanofluids in a tube under laminar and turbulent flow conditions. In this study, it was achieved that the thermal performance of $\mathrm{Al}_{2} \mathrm{O}_{3}$ /water nanofluid improved with increasing nanoparticle volume concentration for $\mathrm{Re}<40.000$. Besides, increasing the nanoparticle volume concentration and Reynolds number led to improve the entropy generation, too. In the experimental study of Singh et al. [8], entropy analysis for $\mathrm{Al}_{2} \mathrm{O}_{3}$ /water nanofluid in microchannels was determined. Accordingly, because of increasing viscosity as a result of increasing the nanoparticle volume concentration, the entropy generation of fluid friction could not be overlooked in microchannel problems. Furthermore, Bianco et al. [9] also studied numerically on entropy generation analysis of $\mathrm{Al}_{2} \mathrm{O}_{3}$ /water nanofluid in a square cross-sectioned channel. According to the study, it was determined that the entropy generation caused by heat transfer irreversibilities were dominant at lower Reynolds numbers, while the entropy generation due to friction losses was dominant at higher Reynolds number and increased with the nanoparticle volume concentrations. Ji et al. [10] investigated numerically the entropy generation analysis of $\mathrm{Al}_{2} \mathrm{O}_{3}$ /water nanofluid in a tube detailly using RANS model. Correspondingly, it was obtained that nanofluid flow at $\mathrm{Re}=50000$ presented an optimal performance at lower wall heat fluxes. Along with increasing heat flux, the obtaining optimal performance of nanofluid flow was also improved. Moreover, Amirahmadi et al. [11] researched the minimization of entropy generation rates in a trapezoidal duct under laminar flow conditions. It was analyzed the effects of beveled corners and surface roughness on exergy losses. Consequently, it was found that the entropy generation was decreased by using vortex generators.

According to the literature, research performing on energy, entropy, and exergy analyses of the hybrid nanofluid with a thermodynamic approach is very limited. Therefore, in this study, the forced convective turbulent flow - $\mathrm{Al}_{2} \mathrm{O}_{3}-\mathrm{Cu}$ /water hybrid nanofluid and the single components of its $\left(\mathrm{Al}_{2} \mathrm{O}_{3} /\right.$ water and $\mathrm{Cu}$ /water) -in a trapezoidal cross-sectioned channel have been thermodynamically investigated under a turbulent flow regime. Unlike the other papers placed in the literature, this study applies both the first and second laws of thermodynamics to find out the thermal performance of the hybrid nanofluids and determine the main source of the entropy generation along the noncircular cross-sectioned channel, respectively. Results of both hybrid and single components have been compared and discussed for different volumetric concentrations (1.0\% and $2.0 \%)$. Thus, an attempt has been made to close the lack in the literature.

\section{Problem Description}

In this study, $\mathrm{Al}_{2} \mathrm{O}_{3}$ /water, $\mathrm{Cu}$ /water nanofluids, and $\mathrm{Al}_{2} \mathrm{O}_{3}-\mathrm{Cu}$ /water hybrid nanofluids have been used as working fluid. To determine the effect of flow and heat transfer characteristics of nanofluid flow on these analyses, a trapezoidal cross-sectioned channel rarely used in the literature has been utilized. This channel is used in compact heat exchangers [12], cooling of mini electronic equipment [13], and cooling passages of the turbine blades [14]. Besides, this cross-section is also utilized in the biomedical field, too. The hydraulic diameter and the length of this channel have been determined as $4.3 \mathrm{~cm}$ and $1.5 \mathrm{~m}$, respectively. The dimensions of the short edges and upper edge are $4 \mathrm{~cm}$ and $6 \mathrm{~cm}$, respectively. Besides, the base angle of the channel is $75^{\circ}$ as depicted in Fig. 1.

As indicated in Fig. 1, the walls of the channel are under the influence of a constant heat flux $\left(q^{\prime \prime}\right)$. In the turbulent regime, different Reynolds numbers ranging from $10^{4}$ to $10^{5}$ are taking into consideration. For numerical analyses, the single-phase model is applied in this study to investigate the thermal and fluid dynamic behavior of hybrid nanofluid and single components of its. In this model, the nanofluid is treated as a homogeneous fluid with effective properties because of nanoparticle addition since the mixture acts as a singlephase fluid [15]. Hence, the Euler-Euler model provides a low computational cost with reasonable accuracy. 
The conservation of mass, momentum, and energy equations must be solved in numerical analyses for determining flow and heat transfer characteristics of the nanofluids. For incompressible, single-phase approach and steady-state flow conditions, continuity, momentum, and energy equations are simplified in that case to vector forms as follows [16]:

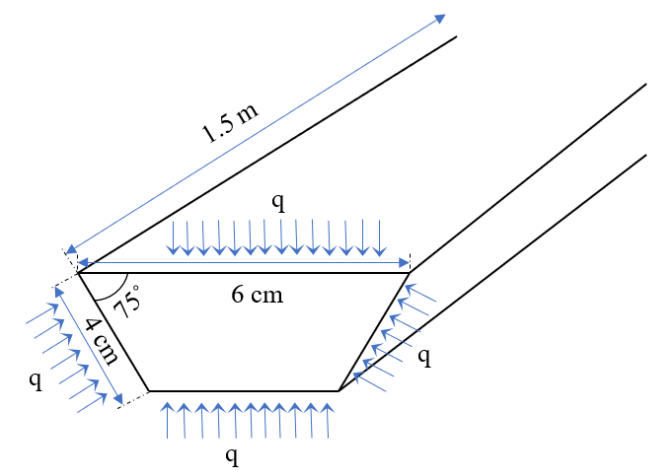

Figure 1. The geometry and dimensions of the trapezoidal cross-sectioned channel.

Continuity Equation:

$$
\vec{\nabla} \cdot \vec{V}=0
$$

Momentum

Equation:

$\rho \frac{D \vec{V}}{D t}+\nabla \cdot(\rho \vec{V} \vec{V})=-\Delta \mathrm{P}+\rho \overrightarrow{\mathrm{g}}+\mu \nabla^{2} \vec{V}$

Energy

$\rho c_{p}\left[\frac{D T}{D t}+\nabla \cdot(\mathrm{TV})\right]=k \nabla^{2} T+\phi$

Equation:

where $V, P$, and $T$ denote the time-averaged variables, i.e, mean velocity, mean pressure, and mean temperature, respectively. $\phi$ is dissipation function representing the work done against viscous forces.

Also, the turbulence models must be used for modeling the turbulent flow. Turbulent convective heat transfer is modeled to close the governing equations of thermofluidic dynamics fields. The well-known semiempirical Standard $\kappa-\varepsilon$ turbulent model, the validity of which is accepted by many researchers and proposed by Launder and Spalding [17] is employed in the present study. This model is also discussed in the study of Namburu et al. [18]. According to the paper, two additional equations namely turbulent kinetic energy, $\kappa$ and the rate of dissipation, $\varepsilon$ are introduced. These equations obtained from the transport equations are given, respectively as follows:

$$
\begin{aligned}
& \frac{\partial}{\partial t}(\rho k)+\frac{\partial}{\partial x_{i}}\left(\rho k u_{i}\right)=\frac{\partial}{\partial x_{j}}\left(\left(\mu+\frac{\mu_{t}}{\sigma_{k}}\right) \frac{\partial k}{\partial x_{j}}\right)+G_{k} \\
& +G_{b}-\rho \varepsilon-Y_{M}+S_{k}
\end{aligned}
$$

$$
\begin{aligned}
& \frac{\partial}{\partial t}(\rho \varepsilon)+\frac{\partial}{\partial x_{i}}\left(\rho \varepsilon u_{i}\right)=\frac{\partial}{\partial x_{j}}\left(\left(\mu+\frac{\mu_{t}}{\sigma_{\varepsilon}}\right) \frac{\partial \varepsilon}{\partial x_{j}}\right) \\
& +C_{1 \varepsilon} \frac{\varepsilon}{k}\left(G_{k}+C_{3 \varepsilon} G_{b}\right)-C_{2 \varepsilon} \rho \frac{\varepsilon^{2}}{k}-S_{\varepsilon}
\end{aligned}
$$

where $G_{\kappa}$ stands for the generation of turbulent kinetic energy due to mean velocity gradients, $G_{b}$ for the generation of turbulent kinetic energy due to buoyance, $Y_{M}$ for the contribution of the fluctuating dilatation incompressible turbulence to the overall dissipation rate. Besides, $\sigma_{k}$ and $\sigma_{\varepsilon}$ represent effective Prandtl numbers for the turbulent kinetic energy and the rate of dissipation, respectively, while $S_{k}$ and $S_{\varepsilon}$ represent userdefined source terms. Furthermore, $C_{1 \varepsilon}, C_{2 \varepsilon}$, and $C_{3 \varepsilon}$ are constants and $\mu_{t}$ denotes the eddy viscosity that can be calculated via the equation given by:

$\mu_{t}=\rho C_{\mu} \frac{k^{2}}{\varepsilon}$

In Eqs. (4) - (6), the constants used for the Standard $\kappa$ $\varepsilon$ turbulence model are given as follows [18]:

$$
C_{1 \varepsilon}=1.44, C_{2 \varepsilon}=1.92, C_{\mu}=0.09, \sigma_{k}=1.0, \sigma_{\varepsilon}=1.3
$$

To solve the governing equations, following assumptions and boundary conditions are considered:

- The flow has been assumed to be incompressible, steady-state, hydrodynamically and thermally fully developed, and turbulent.

- At the inlet section of the channel, a uniform axial velocity and temperature profile have been assigned: $u_{x}=u_{i n}, u_{y}=0 \mathrm{~m} / \mathrm{s}, T=300 \mathrm{~K}$.

- At the outlet section, the atmospheric pressure prevails:

$P=P_{\mathrm{amb}}=101325 \mathrm{~Pa}$

- The constant heat flux of $20 \mathrm{~kW} / \mathrm{m}^{2}$ has been applied to the walls of the channel. The No-slip condition has been applied at the channel walls for hydrodynamic boundary conditions.

- The volumetric concentrations of the nanofluids range from 1.0 to $2.0 \%$.

- Turbulence intensity has been given as boundary condition at the inlet and outlet of the channel. It can be determined by $I=0.16 \operatorname{Re}_{D}^{-1 / 8}$.

\section{Thermophysical Properties of Nanofluid}

Thermophysical properties are conceptually defined as all material characteristics substantially influencing the heat transfer performance and heat storage of the material. The variation in these properties influences thermodynamic and transport characteristics of the nanofluids, thus the flow conditions of the convective heat transfer of the nanofluids through considered geometry change. In this paper, the following equations proposed by Suresh et al. [3] are used to find to what extent their experimental data are appropriate for hybrid nanofluids.

The density of the nanofluids, $\rho$ can be obtained using the general expression for the mixtures as follows [1]: 


$$
\rho_{n f}=(1-\varphi) \rho_{b f}+\varphi \rho_{n p}
$$

where indices $n p, b f$, and $n f$ denote the nanoparticle, base fluid, and single-particle nanofluid, respectively. Besides, $\varphi$ specifies the overall volume concentration of two different types of nanoparticles dispersed in a base fluid (hybrid nanofluid) and can be determined by the expression given below:

$$
\varphi=\varphi_{C u}+\varphi_{\mathrm{Al}_{2} \mathrm{O}_{3}}
$$

Thus, $\rho$ becomes for hybrid nanofluid as:

$$
\rho_{\text {hnf }}=(1-\varphi) \rho_{b f}+\varphi_{C u} \rho_{C u}+\varphi_{\mathrm{Al}_{2} \mathrm{O}_{3}} \rho_{\mathrm{Al}_{2} \mathrm{O}_{3}}
$$

The specific heat capacity of the hybrid nanofluid, $C_{p}$ is calculated by assuming the thermal equilibrium between the base fluid and particle as follows [6]:

$$
\begin{aligned}
& \left(\rho C_{p}\right)_{h n f}=(1-\varphi)\left(\rho C_{p}\right)_{b f}+\varphi\left(\rho C_{p}\right)_{n p} \\
& \left(C_{p}\right)_{h n f}=\frac{(1-\varphi)\left(\rho C_{p}\right)_{b f}+\varphi_{C u}\left(\rho C_{p}\right)_{C u}+\varphi_{\mathrm{Al}_{2} \mathrm{O}_{3}}\left(\rho C_{p}\right)_{\mathrm{Al}_{2} \mathrm{O}_{3}}}{\rho_{h n f}}
\end{aligned}
$$

The effective thermal conductivity of the nanofluid, knf can be obtained from the basis of the classical analysis proposed by Maxwell [19] for two-phase mixtures given by:

$$
\frac{k_{n f}}{k_{b f}}=\frac{k_{n p}+2 \cdot k_{b f}-2 \cdot \varphi\left(k_{b f}-k_{n p}\right)}{k_{n p}+2 \cdot k_{b f}+\varphi\left(k_{b f}-k_{n p}\right)}
$$

Therefore, Eq. (13) can be developed to define the thermal conductivity of $\mathrm{Al}_{2} \mathrm{O}_{3}-\mathrm{Cu}$ /water hybrid nanofluid [1]. Thus, Eq. (14) can be derived for determining $k_{n f}$ as below:

$$
\frac{k_{h n f}}{k_{f}}=\frac{\left(\varphi_{C u} k_{C u}+\varphi_{\mathrm{A}_{2} \mathrm{O}_{3}} k_{\mathrm{Al}_{2} \mathrm{O}_{3}}\right) /(\varphi)+2 k_{b f}+2\left(\varphi_{\mathrm{Cu}} k_{\mathrm{Cu}}+\varphi_{\mathrm{Al}_{2} \mathrm{O}_{3}} k_{\mathrm{Al}_{2} \mathrm{O}_{3}}\right)-2(\varphi)\left(k_{b f}\right)}{\left(\varphi_{\mathrm{Cu}} k_{\mathrm{Cu}}+\varphi_{\mathrm{Al}_{2} \mathrm{O}_{3}} k_{\mathrm{Al}_{2} \mathrm{O}_{3}}\right) /(\varphi)+2 k_{b f}-\left(\varphi_{C u} k_{C u}+\varphi_{\mathrm{Al}_{2} \mathrm{O}_{3}} k_{\mathrm{Al}_{2} \mathrm{O}_{3}}\right)+(\varphi)\left(k_{b f}\right)}
$$

The dynamic viscosity of nanofluid, $\mu_{\mathrm{nf}}$ can theoretically be estimated by three models as Einstein [20], Brinkman [21], and Batchelor [22]. However, in this study, following expression proposed by Brinkman is used:

$$
\mu_{n f}=\frac{\mu_{b f}}{(1-\varphi)^{2.5}}
$$

If $\varphi$ in Eq. (9) is substitued in Eq. (15), it becomes as:

$$
\mu_{h n f}=\frac{\mu_{b f}}{\left(1-\left(\varphi_{C u}+\varphi_{\mathrm{Al}_{2} \mathrm{O}_{3}}\right)\right)^{2.5}}
$$

Table 1. Thermophysical properties of water, $\mathrm{Cu}$, and $\mathrm{Al}_{2} \mathrm{O}_{3}$ nanoparticles and hybrid nanofluid.

\begin{tabular}{lccccc}
\hline Material & Water & $\mathbf{C u}$ & $\mathrm{Al}_{2} \mathbf{O}_{3}$ & $\begin{array}{c}\mathbf{1 . 0 \%} \\
\text { Hybrid } \\
\text { Nanofluid }\end{array}$ & $\begin{array}{c}\mathbf{2 . 0 \%} \\
\text { Hybrid } \\
\text { Nanofluid }\end{array}$ \\
\hline $\begin{array}{l}\text { Density } \\
\left(\mathrm{kg} / \mathbf{m}^{\mathbf{3}}\right)\end{array}$ & 995.7 & 8940 & 3970 & 1027.78 & 1059.86 \\
\hline $\begin{array}{l}\text { Viscosity } \\
(\mathrm{kg} / \mathbf{m} \cdot \mathbf{s})\end{array}$ & 0.798 & - & - & 1.602 & 1.935 \\
\hline $\begin{array}{l}\text { Thermal } \\
\text { conductivity }\end{array}$ & 0.615 & 400 & 40 & 0.657 & 0.685 \\
\hline
\end{tabular}

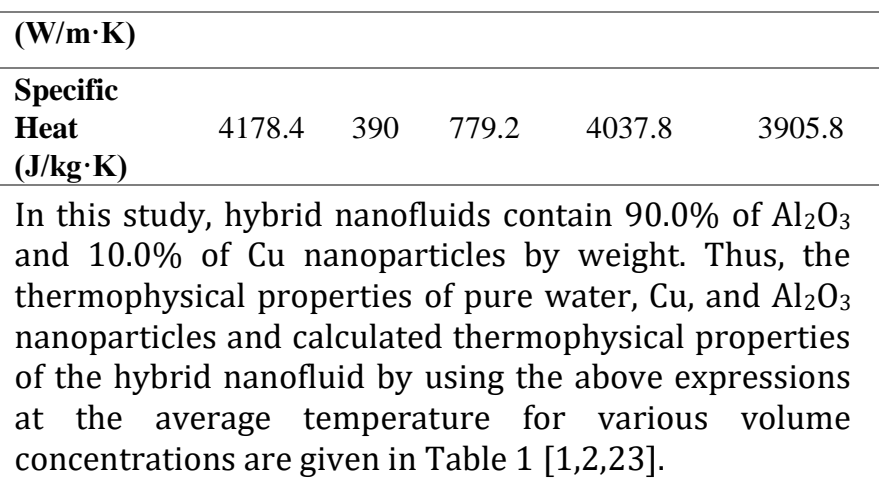

\section{Thermodynamic Analyses}

\subsection{Energy Analysis}

Since the convection is energy transfer between a solid surface and an adjacent gas or liquid by the combined effects of conduction and bulk fluid motion within the gas or liquid, the average convective heat transfer coefficient, $h$ and average Nusselt number, $\mathrm{Nu}$ are two fundamental parameters that are used to find out the thermal performance of the nanofluids and defined as follows:

$$
h=\frac{q^{\prime}}{\left(T_{w}-T_{b}\right)_{\text {avg }} P_{c}}
$$

where $q^{\prime}$ and $P_{c}$ denote the heat flux applied at the channel wall per meter, and the perimeter of the crosssection, respectively. Besides, $T_{w}$ and $T_{b}$ denote the linear mean temperature difference of the wall, and the bulk temperature of the nanofluid flow, respectively. Here, $T_{b}$ can be determined by taking average temperatures of the nanofluids at the inlet and the outlet sections of the channel as given:

$T_{b}=\frac{T_{\text {in }}+T_{\text {out }}}{2}$

The Nusselt number, $\mathrm{Nu}$ for a fully developed internal flow is the ratio of the average convective heat transfer $h$, the hydraulic diameter of the trapezoidal channel $D_{h}$, and the thermal conductivity of the nanofluid $k$, as shown in Eq. (20):

$$
N u=\frac{h D_{h}}{k}
$$

Apart from these parameters, the Reynolds number, $R e$, used to help predict flow patterns in different fluid flow situations is taking into consideration. Considering the flow in the channel, $R e$ is defined as:

$\operatorname{Re}=\frac{\rho V D_{h}}{\mu}$

Besides, Prandtl number, $P r$ can be obtained as functions of the specific heat capacity $C_{p}$, dynamic viscosity $\mu$, and thermal conductivity of the nanofluid $k$, as follows:

$\operatorname{Pr}=\frac{C_{p} \mu}{k}$ 
The average Darcy friction factor, $f$ can be obtained from Darcy-Weisbach expression as a dimensionless representation of the pressure drop under isothermal flow conditions given below [21]:

$$
f=\frac{\Delta P}{\left(\frac{L}{D_{h}}\right) \cdot\left(\frac{\rho \cdot V^{2}}{2}\right)}
$$

where $\Delta P$ and $L$ denote the pressure drop between inlet and outlet, and the length of the channel, respectively.

In order to characterize the energetic or thermal performance of a nanofluid flowing inside a channel, performance evaluation criterion, $P E C$ that takes the ratio of heat transfer enhancement and friction factor increase at the same Reynolds number, can be used. This method is based on an energetic global approach and considers the effect of additional pumping power resulting from using nanofluid instead of the base fluid. Therefore, in case of identical pumping power, pressure drop, and flow rate, it can be defined as follows [24]:

$$
P E C=\frac{\left(N u_{\text {enhanced }} / N u_{\text {base }}\right)}{\left(f_{\text {enhanced }} / f_{\text {base }}\right)^{1 / 3}}
$$

\subsection{Entropy Analysis}

Entropy can be characterized as an extensive property that becomes somewhat more meaningful when the microscopic state of the system and its surroundings is considered. Accordingly, the total entropy generation rate per the length of the channel due to heat transfer (with finite temperature difference) and flow friction during the turbulent flow through the trapezoidal channel is expressed as follows:

$$
\dot{S}_{g e n}^{\prime}=\dot{S}_{g e n, \text { heat transser }}^{\prime}+\dot{S}_{g e n, \text { fluid friction }}^{\prime}
$$

For simplicity, if a small passage of length $\mathrm{dx}$ is considered as the thermodynamic system, the first law of thermodynamics can be written as [25]:

$\dot{m} d h=q^{\prime} d x$

Hence, the correlation above becomes:

$\dot{S}_{g e n}^{\prime}=\frac{\dot{m} d s}{d x}-\frac{q^{\prime}}{T+\Delta T}$

where $T$ denotes the fluid bulk temperature. For an incompressible fluid, the Gibbs equation [26] can be given as:

$$
T d s=d h-v d P
$$

where $v$ denotes the specific volume expressed as:

$v=\frac{1}{\rho}$

If the expressions between Eqs. (27) and (30) are combined, the entropy generation rate, $\dot{S}_{g e n}^{\prime}$ is obtained as follows:

$$
\dot{S}_{g e n}^{\prime}=\frac{q^{\prime} \Delta T}{T^{2}+T \Delta T}+\frac{\dot{m}}{T \rho}\left(-\frac{d P}{d x}\right)
$$

In Eq. (31), the differential form of pressure drop across the system, $P$ can be derived as given:

$-\frac{d P}{d x}=f \frac{\rho V^{2}}{2 D_{h}}=f \frac{\rho V^{2} P_{c}}{8 A_{c}}$

Since the mass flow rate, $\dot{m}$ is defined as:

$\dot{m}=\rho V A_{c}$

Using this relation, the above equation can be simplified as:

$-\frac{d P}{d x}=\frac{\dot{m}^{2} \cdot f \cdot P_{c}}{8 \rho A_{c}^{3}}$

If $\Delta T$ is left alone on the left hand side in Eqs. (17) and (19), it is determined as:

$$
\Delta T=\frac{q^{\prime}}{h \cdot P_{c}}=\frac{q^{\prime}}{\frac{N u \cdot k}{D_{h}} \cdot P_{c}}=\frac{q^{\prime}}{N u \cdot k \cdot \frac{P_{c}^{2}}{4 A_{c}}}=\frac{4 q^{\prime} \cdot A_{c}}{N u \cdot k \cdot P_{c}^{2}}
$$

Finally, a generalized entropy generation rate for a trapezoidal cross-sectioned channel is obtained by using Eqs. (29), (33) and (34):

$$
\dot{S}_{g e n}^{\prime}=\frac{4\left(q^{\prime}\right)^{2} \cdot A_{c}}{T^{2} N u \cdot k \cdot P_{c}^{2}+4 T \cdot q^{\prime} \cdot A_{c}}+\frac{f \cdot \rho V^{3} \cdot P_{c}}{8 T}
$$

The entropy generation in the considered channel is dominated by two factors as indicated in Eq. (24). To determine the contributions of these factors, a dimensionless number called the Bejan number, $B e$ is introduced in Eq. (37). Accordingly, Be is defined as a ratio of entropy generation of heat transfer to the total entropy generation and it is given by:

$$
B e=\frac{\dot{S}_{\text {gen, heat transfer }}^{\prime}}{\dot{S}_{\text {gen, heat transfer }}^{\prime}+\dot{S}_{\text {gen, fluid friction }}^{\prime}}
$$

\subsection{Exergy Analysis}

Exergy is defined as a universal measure of the work potential or the maximum amount of work that can be obtained from a great variety of streams (mass, heat, and work) that flow through a system. The concept of exergy comes from the second law of thermodynamics in which both the quality and quantity of different forms of energy (ordered or disordered) are taking into consideration together. With this approach, assuming that the turbulent flow is steady-state, incompressible and hydrodynamically as well as thermally fully developed, the rate of exergy at the inlet of flowing fluid is given by [6]:

$$
E x_{i n}=\dot{m} C_{p}\left[\left(T_{i n}-T_{\infty}\right)-T_{\infty} \ln \left(T_{i n} / T_{\infty}\right)\right]
$$

Besides, the outlet exergy rate of flowing fluid is given as follows:

$$
E x_{\text {out }}=\dot{m} C_{p}\left[\left(T_{\text {out }}-T_{\infty}\right)-T_{\infty} \ln \left(T_{\text {out }} / T_{\infty}\right)\right]
$$


where, $T_{\infty}$ is the ambient temperature.

A pump is essential to maintain a constant flow across the channel. Accordingly, the required pumping power is determined as:

$P_{p}=\frac{\dot{m}}{\rho} \Delta P$

Thus, exergy destruction can be calculated given by:

$E x_{\text {dest }}=E x_{\text {in }}-E x_{\text {out }}+E x_{P_{p}}+E x_{Q}$

where $E x_{P_{p}}$ and $E x_{Q}$ represents the exergy of pumping power and total heat transfer.

For heating applications in channels, exergy efficiency can be obtained as follows:

$\Psi_{n f}=\frac{E x_{\text {out }}}{E x_{i n}+E x_{P_{p}}+E x_{Q}}$

\section{Numerical Computations}

Steady-segregated solver is used with a second-order upwind scheme for convective terms in the mass, momentum, energy, and turbulence equations. For pressure discretization, the standard scheme has been used while the SIMPLE-algorithm has been employed for pressure-velocity coupling discretization. Governing equations have been iterated until the residual terms fall below $10^{-6}$. The inlet temperature is taken as $300 \mathrm{~K}$.

In this study, the highest Reynolds number is determined as $10^{5}$ and the mesh study has been completed at this Reynolds number. As indicated in Fig. 2 , increasing mesh number cause a relative variation in the Nusselt number. However, the Nusselt number nearly remains constant after the mesh number reaches the value of 354000 . After that point, the Nusselt number repeats itself. Hence, the mesh number of 354,000 has been selected as the optimum mesh number for this study.

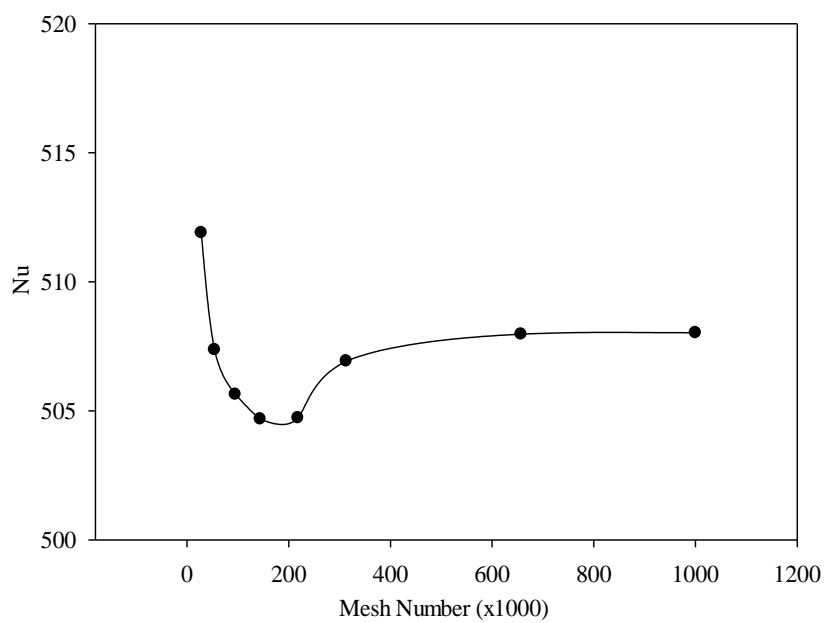

Figure 2. Variation of average Nusselt number with mesh number.

After obtaining the optimum mesh number, analyses related to water have been conducted. The numerical study results have been tested with well-known correlations obtaining from experimental data in the literature. Accordingly, it is obtained that the numerical results are compatible with these correlations as shown in Fig. 3. These results are almost the same at the low Reynolds number; however, the difference between the present study and other correlations given in the literature increases in case to higher Reynolds number. Specifically, the compatibility of analysis results is in the range of $5.0 \%$ error margin for Sieder-Tate relation, and in \%10.0 error margin for Dittus-Boelter and Gnielinski relations in general.

Fig. 4 presents the variation of convective heat transfer coefficient of nanofluids depending on Reynolds number for different nanoparticle volume fractions. According to the figure, the convective heat transfer of the base fluid, hybrid, and single-particle nanofluids increase with increasing Reynolds numbers. Besides, the nanoparticle volume concentration provides an enhancement in the turbulent heat transfer coefficient of $\mathrm{Al}_{2} \mathrm{O}_{3} /$ water nanofluid as well as that of $\mathrm{Al}_{2} \mathrm{O}_{3}-\mathrm{Cu}$ /water hybrid nanofluid.

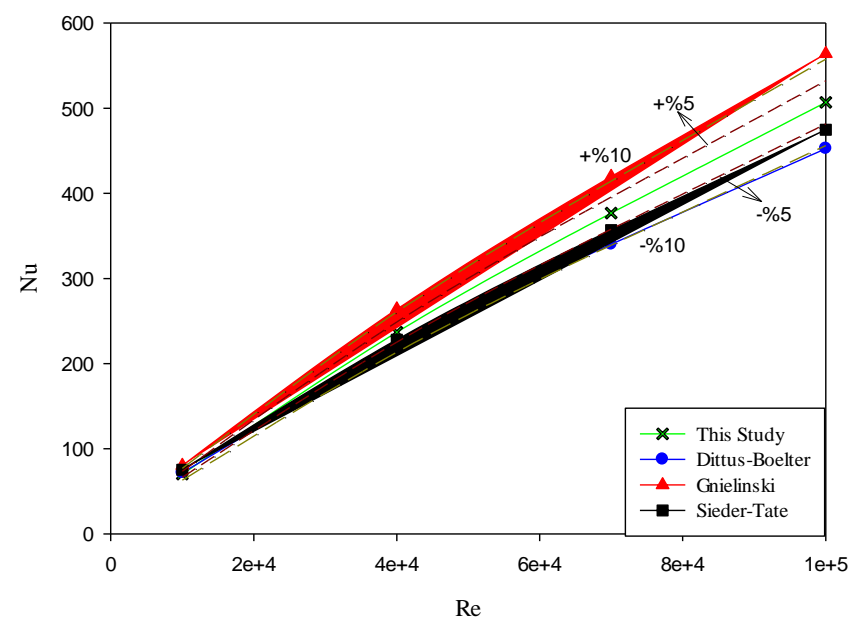

Figure 3. Comparison of the numerical results with correlations in the literature.

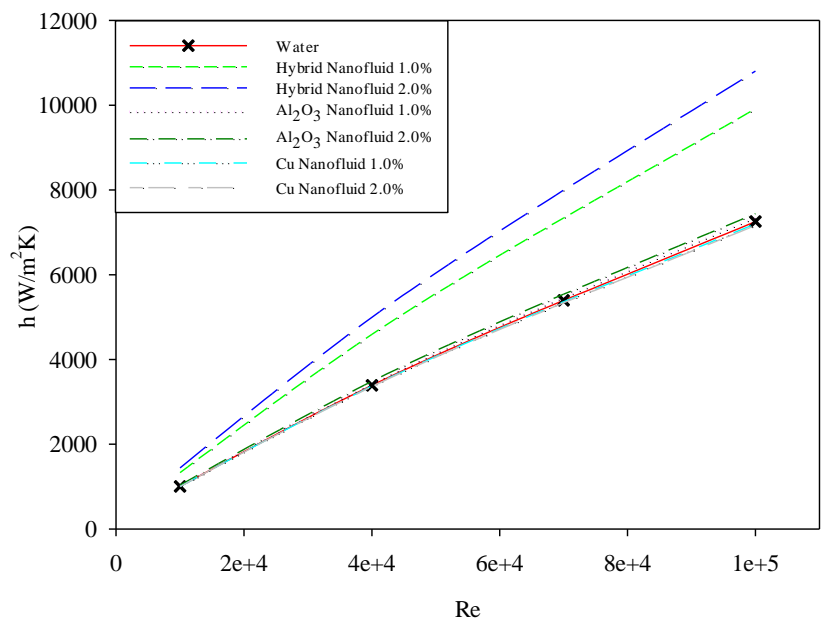

Figure 4. Variation of convective heat transfer coefficient of nanofluids with Reynolds number. 
This is considered to be due to the improvement of the thermophysical properties of the mixture, along with the inclusion of particles. Due to the nature of dispersed nanoparticles which modifies the thermodynamic and transport properties of the mixture, the hybrid nanofluid offers superior convective heat transfer comparing to the base fluid. This enhancement is reached up to $49.0 \%$ in $\mathrm{Al}_{2} \mathrm{O}_{3}-\mathrm{Cu} /$ water hybrid nanofluid with a volume concentration of $2.0 \%$ in the present study. Followingly, the hybrid nanofluid with a volume concentration of $1.0 \%$ has performed a remarkable difference comparing to the single-particle nanofluids and pure water. Therefore, it is clearly found out that the performance of the hybrid nanofluid in the convective heat transfer is higher than that of nanofluid in the same volumetric concentration.

\section{Results and Discussion}

Fig. 5 demonstrates the variation of Darcy friction factor of nanofluids with respect to Reynolds number. Accordingly, the friction factor of the base fluid, hybrid, and single-particle nanofluids gradually decrease over a range of Reynolds numbers. Besides, the friction factor of hybrid nanofluid does not change significantly comparing to that of nanofluid with the same volume concentration and the base fluid, even though viscosities of hybrid, and single-particle nanofluids are higher than the base fluid. However, the friction factors of $\mathrm{Cu}$ /water nanofluid appear slightly smaller than the base fluid, hybrid, and $\mathrm{Al}_{2} \mathrm{O}_{3}$ /water nanofluids. Unlike the convective heat transfer coefficient, the nanoparticle volume concentration has no positive impact on the friction factor in a fixed Reynolds number.

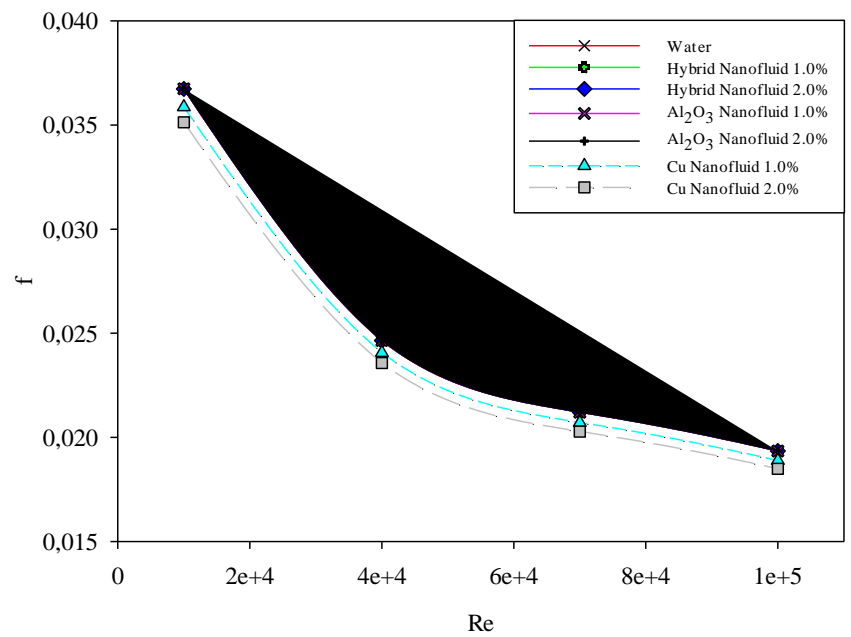

Figure 5. Variation of Darcy friction factor of nanofluids with Reynolds number.

Fig. 6 illustrates the variation of Performance Evaluation Criteria (PEC) with Reynolds number. Accordingly, it is determined that the best thermal performance is obtained in $\mathrm{Al}_{2} \mathrm{O}_{3}-\mathrm{Cu}$ /water hybrid nanofluids and this performance enhancement is reached $34.0 \%$ in the hybrid nanofluid with a volume concentration of $2.0 \%$. This is followed by the hybrid nanofluid with a volume concentration of $1.0 \%$ just after. Therefore, it is understood that the influence of the nanoparticle volume concentration provides a positive contribution to hybrid nanofluids. Besides, the $P E C$ value of hybrid nanofluids increases along with increasing Reynolds number, whereas the same value for $\mathrm{Al}_{2} \mathrm{O}_{3}$ and $\mathrm{Cu} /$ water nanofluids appears to very slight decline over this range. Here, it is worth mentioning that single-particle nanofluids are overwhelmed by the friction forces, therefore the heat transfer enhancement of the nanofluids could not be dominant over the fluid friction.

Fig. 7 depicts the variation of entropy generation of nanofluids with respect to Reynolds number. According to the figure, the entropy generation of the base fluid, hybrid, and single-particle nanofluids substantially decrease with increasing Reynolds number. However, the most significant decline has been observed in hybrid nanofluids in a way that the values of $1.0 \%$ nanoparticle volume concentration appear higher than those of $2.0 \%$ volume concentration. This behavior can be explained with that the nanoparticle volume concentration improves transport and thermophysical characteristics, thus the convective heat transfer coefficient and thermal performance of the nanofluid increases, finally the entropy generation in the channel is minimized, and a better heat transfer is achieved. On the other hand, a related point to consider is that the entropy generation of the pure water and single-particle nanofluids is higher than the hybrid nanofluids, thus the heat transfer performance of these nanofluids is obtained as lower than hybrids.

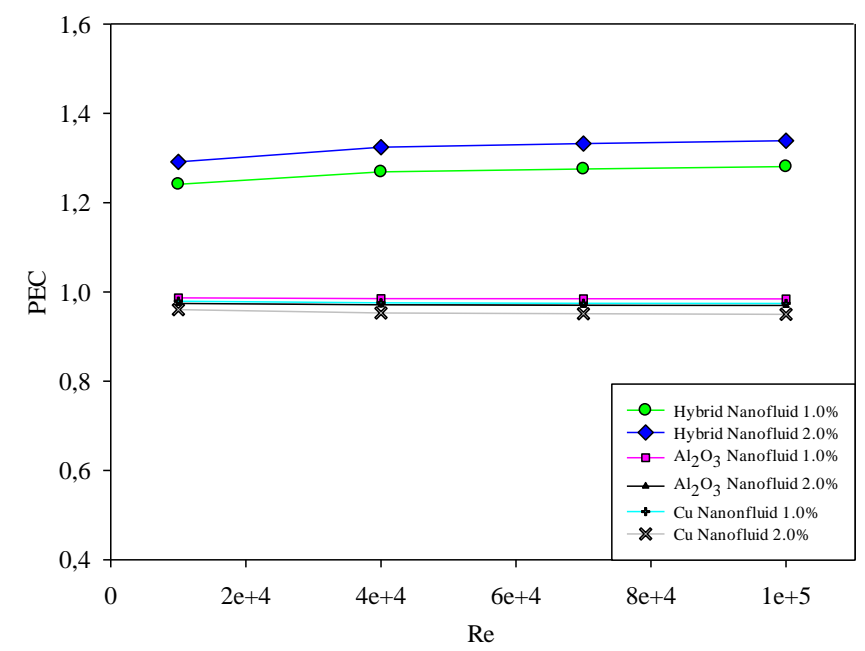

Figure 6. Variation of PEC with Reynolds number. 


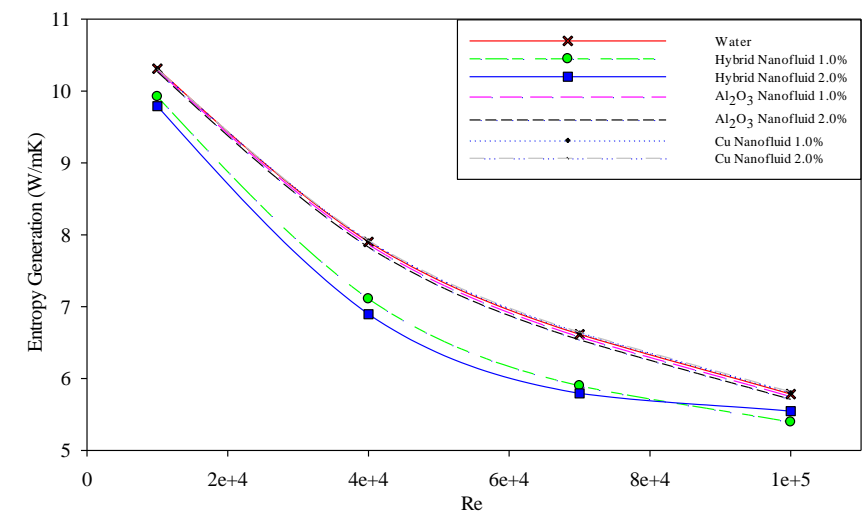

Figure 7.Entropy generation of nanofluids with Reynolds number.

Fig. 8 displays the variation of entropy generation along the channel wall. As it has been pointed out in the figure, the entropy generation in the inlet section of the channel occurs from the hydrodynamic effect. Afterward, the heat transfer effect of the entropy generation dominates the entire section. Due to the low local velocity magnitudes and high local heat transfer, the entropy generation becomes more apparent at the edges of the channel.

Apart from the analysis of the total entropy generation, the main sources that cause the entropy generation can also be examined. In Fig. 9, the variation of the entropy generation resulting from the heat transfer and fluid friction for different nanoparticle volume concentrations, and corresponding total entropy generation rates are given for a fixed Reynolds number $\left(10^{5}\right)$. According to the figure, the entropy generation from the fluid friction becomes more distinct for hybrid nanofluids because these nanofluids increase the convective heat transfer, thus the heat transfer performs more efficiently. Besides, the volume concentration does not make a remarkable difference for singlenanoparticle nanofluids.

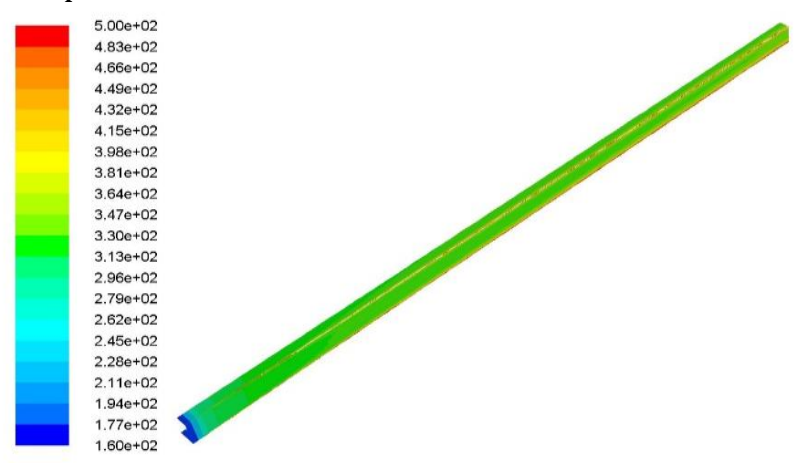

Figure 8. Variation of entropy generation along the channel wall.

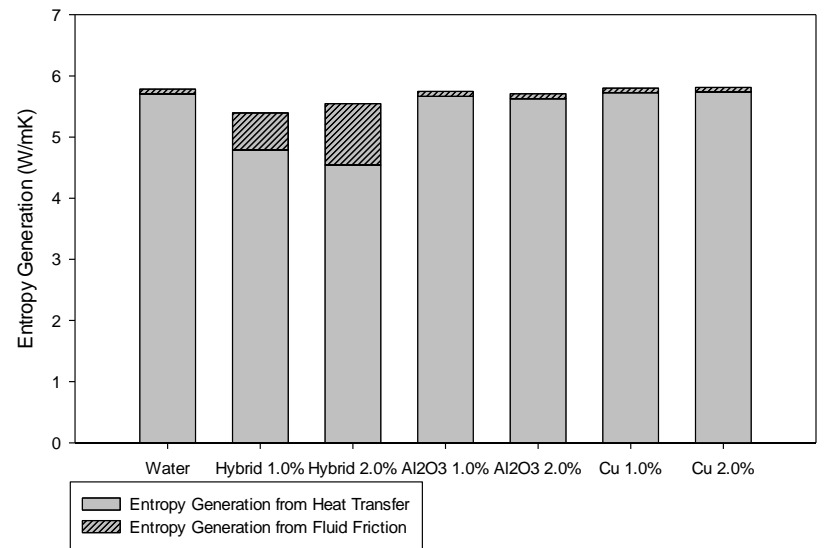

Figure 9. Entropy generation of nanofluids from heat transfer and fluid friction at $\operatorname{Re}=10^{5}$.

Fig. 10 shows that the variation of Bejan number with respect to Reynolds number. Bejan number of all types of fluid decreases along with increasing Reynolds number. Besides, Bejan number of the single particle nanofluids and pure water appears considerably higher because hybrid nanofluids have experienced a dramatic decline in Bejan number. This behaviour can be explained by the increase of the fluid friction. As mentioned previously, hybrid nanofluids offer better heat transfer performance; however, the entropy generation from the fluid friction is higher than the base fluid and single particle nanofluids. Hence, the ratio of entropy generation from the fluid friction over total entropy generation becomes higher. This situation causes to be obtained lower Bejan number in hybrid nanofluids. For comparison purposes, the greatest decline in Bejan number has been in the hybrid nanofluid with a volume concentration of $2.0 \%$. Therefore, it is found that the nanoparticle volume concentration has a negative impact on Bejan number for hybrid nanofluids.

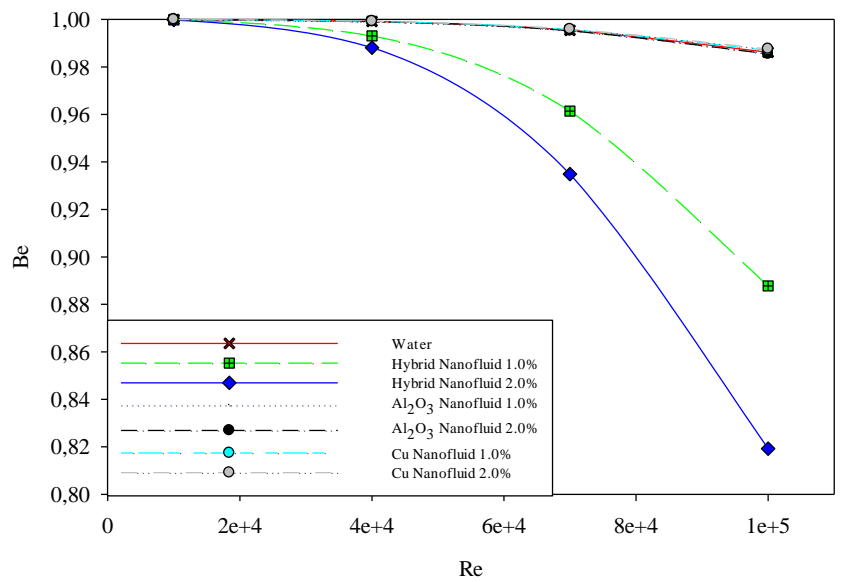

Figure 10. Variation of Bejan number with Reynolds number.

The total entropy generation of hybrid nanofluids is relatively lower comparing to the the single particle nanofluids and pure water. This situation leads to increase the thermal performance or energetic 
efficiency of the hybrid nanofluid, thus a better heat transfer is performed. Another point to consider is that having lower the entropy generation in hybrid nanofluids also makes it possible to have a low exergy destruction as demonstrated in Fig. 11. Accordingly, the exergy destruciton of all types of fluid in a fixed temperature $(273 \mathrm{~K})$ decreases with increasing Reynolds number. Besides, the exergy destruction of the single particle nanofluids and pure water appears remarkably higher than hybrid nanofluids. On the other hand, the exergy destruction rate of the hybrid nanofluid with a volume concentration of $2.0 \%$ has experienced a sharply decline comparing to that of nanofluid with a volume concentration of $1.0 \%$ over a range of Reynolds number. This behaviour gives appropriate clues about the role of the entropy generation on the exergy destruction rate.

There is an inverse ratio between the exergy efficiency and total entropy generation rate. The fluid friction decreases with increasing Reynolds number, thus the entropy generated due to irreversibilities decreases over this range. This situation causes to reduce of the total entropy generation and correspondingly the exergy destruction rate remains lower. As a result, the exergy efficiency gradually increases for all types of fluid as shown in Fig. 12. According to the figure, the exergy efficiency of hybrid nanofluids appears considerably higher than the single particle nanofluids and pure water. Besides, increasing of the nanoparticle volume concentration clearly helps to enhance the exergy efficiency for hybrid nanofluids. Thus, the best exergetic performance has been observed in the hybrid nanofluid with a volume concentration of $2.0 \%$ comparing to all types of nanofluids. Specifically, the exergy efficiency is augmented from $49.37 \%$ at $\operatorname{Re}=10^{4}$ to $89.7 \%$ at $\mathrm{Re}=10^{5}$ in this type of nanofluid. This exergetic performance enhancement is followed by the hybrid nanofluid with a volume concentration of $1.0 \%$, thus the exergy efficiency is augmented from $45.95 \%$ to $88.24 \%$ along with increasing Reynolds number. On the other hand, the exergy efficiencies of the single particle nanofluids and pure water are very close to each other and have a similar trend. Therefore, as it has been pointed out previously, hybrid nanofluids offer lower entropy generation and exergy destruction, in consequence, present better exergy efficiency and heat transfer performance.

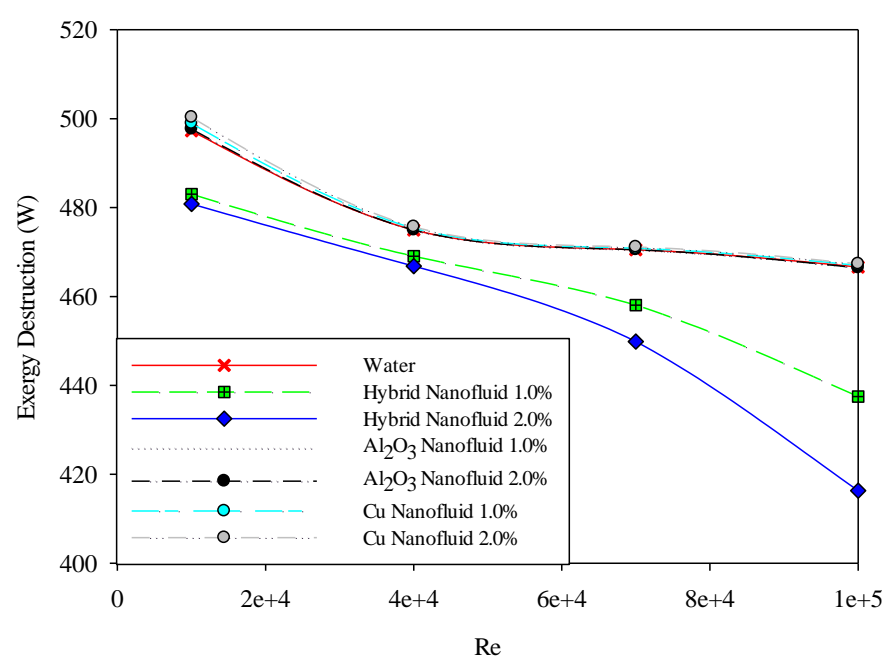

Figure 11. Variation of exergy destruction with Reynolds number at $273 \mathrm{~K}$.

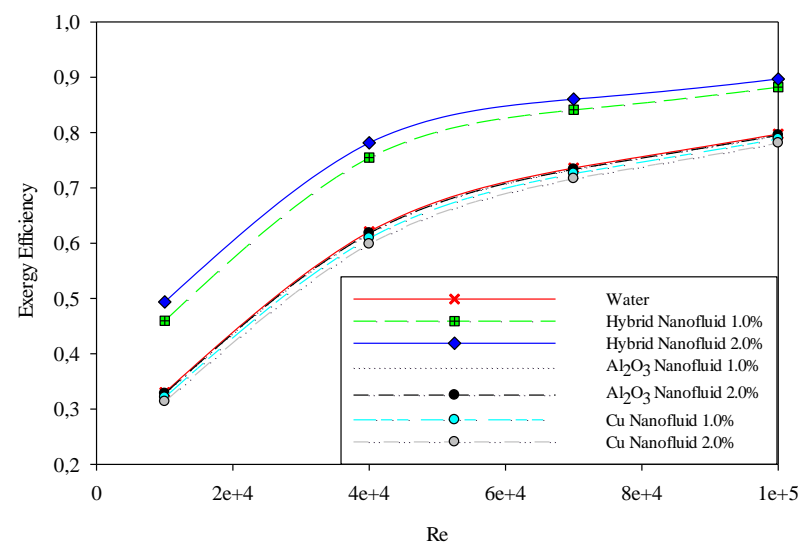

Figure 12. Variation of exergy efficiency with Reynolds numbers at $273 \mathrm{~K}$.

The variation of exergy efficiency with respect to the ambient temperature can also be obtained as illustrated in Fig. 13. According to the figure, the exergy effiency of both hybrid nanofluids and pure water decreases with increasing the ambient temperature. In parallel with this, the maximum exergy efficiency is obtained at 253 $\mathrm{K}$, whereas the minimum effiency rate is obtained at 293 $\mathrm{K}$. Besides, it is observed that the efficiency drop with respect to the temperature is more gradual at $\operatorname{Re}=10^{5}$, whereas it is more steep at $\mathrm{Re}=10^{4}$. In comparison, the most dramatic decline at the range of $\left(10^{4}<\operatorname{Re}<10^{5}\right)$ has been observed in the pure water. Considering the minimum and maximum exergy efficiency rate of pure water, the efficiency drop is determined as $77.82 \%$ and $91.45 \%$ for $\operatorname{Re}=10^{5}$ and $\operatorname{Re}=10^{4}$, respectively. Finally, the exergy efficiency rates at $\mathrm{Re}=10^{5}$ are remarkably higher then those rates at $\mathrm{Re}=10^{4}$. This behaviour proves that the exergy efficiency of all types of nanofluids increase along with the increasing Reynolds number. 


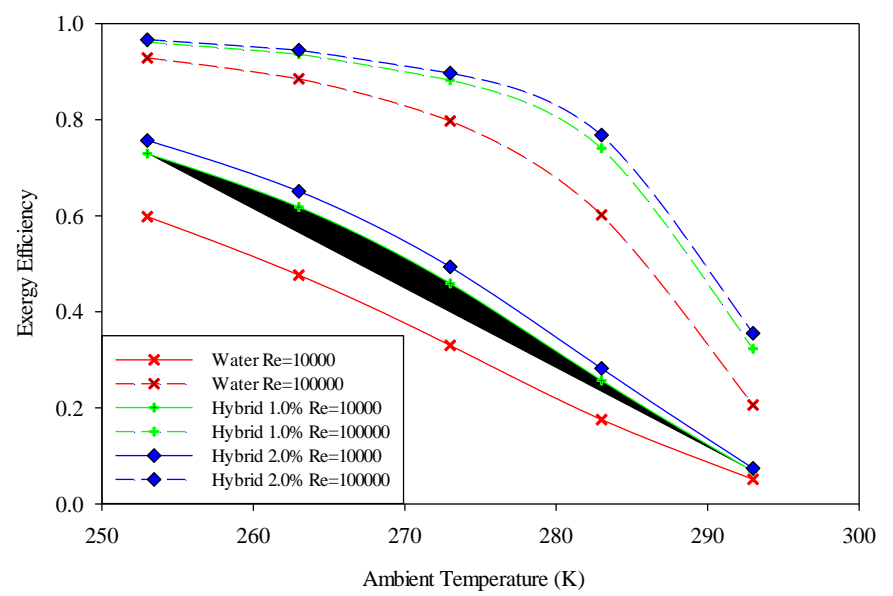

Figure 13. Variation of exergy efficiency with ambient temperature.

\section{Conclusion}

In this study, an attempt has been made to perform energy, entropy and exergy analyses of $\mathrm{Al}_{2} \mathrm{O}_{3}-\mathrm{Cu}$ /water hybrid nanofluid and single particles of the hybrid nanofluid $\left(\mathrm{Al}_{2} \mathrm{O}_{3} /\right.$ water and $\mathrm{Cu} /$ water $)$ with a thermodynamic approach. The flow of these types of nanofluids in a trapezoidal cross-sectioned channel under turbulent flow regime $\left(10^{4}<\mathrm{Re}<10^{5}\right)$ have been numerically investigated for the first time. Besides, analysis results of both hybrid and single particles nanofluids have been compared and discussed for different volumetric concentrations. Accordingly, the main findings that can be drawn from the present study are given below:

- Hybrid nanofluids have higher convective heat transfer coefficient comparing to the base and single particle nanofluids over a range of Reynolds numbers. The enhancement in turbulent heat transfer coefficient is reached to $49.0 \%$ in $\mathrm{Al}_{2} \mathrm{O}_{3}-$ $\mathrm{Cu}$ /water hybrid nanofluid with a volume concentration of $2.0 \%$.

- Among all types of fluid, the best thermal performance is obtained in $\mathrm{Al}_{2} \mathrm{O}_{3}-\mathrm{Cu}$ /water hybrid nanofluids and the performance enhancement is reached up to $34.0 \%$ in the hybrid nanofluid with a volume concentration of $2.0 \%$.

- The exergy efficiency of hybrid nanofluids is considerably higher than the single particle nanofluids and pure water. In comparison, the best exergetic performance has been observed in the hybrid nanofluid with a volume concentration of $2.0 \%$.

- The exergy effiency of the hybrid nanofluid and pure water decreases with increasing the ambient temperature. However, the most dramatic decline been observed in the pure water. Besides, the exergy efficiency rates at $\mathrm{Re}=10^{5}$ are remarkably higher than those rates at $\mathrm{Re}=10^{4}$.

\section{References}

1. Takabi, B. and Shokouhmand, H., "Effects of $\mathrm{Al}_{2} \mathrm{O}_{3}-\mathrm{Cu}$ /water hybrid nanofluid on heat transfer and flow characteristics in turbulent regime," Int. J. Mod. Phys. C, vol. 26, no. 4, p. 1550047, 2015.

2. Selvakumar, P. and Suresh, S., "Use of $\mathrm{Al}_{2} \mathrm{O}_{3}$ $\mathrm{Cu}$ /water Hybrid Nanofluid in an Electronic Heat Sink," IEEE Trans. Components, Packag. Manuf. Tech., vol. 2, no. 10, pp. 1600-1607, 2012.

3. Suresh, S., Venkitaraj, K. P., Selvakumar, P., and Chandrasekar, M., "Effect of Al2O3-Cu/water hybrid nanofluid in heat transfer", Experimental Thermal And Fluid Science, 38: 54-60 (2012).

4. Suresh, S., Venkitaraj, K. P., Selvakumar, P., and Chandrasekar, M., "Synthesis of $\mathrm{Al} 2 \mathrm{O3}-\mathrm{Cu} /$ water hybrid nanofluids using two step method and its thermo physical properties", Colloids And Surfaces A: Physicochemical And Engineering Aspects, 388 (1-3): 41-48 (2011).

5. Moghadassi, A., Ghomi, E., and Parvizian, F., "A numerical study of water based $\mathrm{Al} 2 \mathrm{O} 3$ and Al203-Cu hybrid nanofluid effect on forced convective heat transfer", International Journal of Thermal Sciences, 92: 50-57 (2015).

6. Ahammed, N., Asirvatham, L. G., and Wongwises, S., "Entropy generation analysis of graphenealumina hybrid nanofluid in multiport minichannel heat exchanger coupled with thermoelectric cooler", International Journal of Heat And Mass Transfer, 103: 1084-1097 (2016).

7. Moghaddami, M., Mohammadzade, A., and Esfehani, S. A. V., "Second law analysis of nanofluid flow", Energy Conversion And Management, 52 (2): 1397-1405 (2011).

8. Singh, P. K., Ahmed, N. Z., Das, S. K. and Shatilla, Y., "Exergy Analysis of Nanofluids In Microchannel", 9 ${ }^{\text {th }}$ International Conference on Nanochannels, Microchannels, and Minichannels (ICNMM2011), Alberta, Canada, pp. 1-9, June 1922, 2011.

9. Bianco, V., Nardini, S. and Manca, O., "Enhancement of heat transfer and entropy generation analysis of nanofluids turbulent convection flow in square section tubes," Nanoscale Research Letters, vol. 6, no. 252, pp. 112, 2011.

10. Ji, Y., Zhang, H., Yang, X. and Shi, L., "Entropy Generation Analysis and Performance Evaluation of Turbulent Forced Convective Heat Transfer to Nanofluids," Entropy, vol. 19, no. 108, pp. 1-18, 2017.

11. Amirahmadi, S., Rashidi, S., and Abolfazli Esfahani, J., "Minimization of exergy losses in a trapezoidal duct with turbulator, roughness and beveled corners", Applied Thermal Engineering, 107: 533-543 (2016).

12. London, W. M. K. and A. L., "Compact Heat 
Exchangers", McGraw-Hill, New York, USA, (1964).

13. Dhariwal, S. M. F. and R. S., "Experimental and Numerical Investigation Into the Flow Characteristics of Channels Etched in silicon", Journal of Fluids Engineering, 120: 291-295 (1998).

14. Lee, S. W., "Heat Transfer Characteristics of a Two-Pass Trapezoidal Channel and a Novel Heat Pipe", Texas A\&M University, (2007).

15. Minea, A. A., "Challenges in hybrid nanofluids behavior in turbulent flow: Recent research and numerical comparison," Renewable and Sustainable Energy Reviews, vol. 71, pp. 426-434, 2017.

16. "Fluent Theory Guide", Ansys Inc.

17. B. E. Lauder and D. B. Spalding, "Lectures in Mathematical Models of Turbulence", Academic Press, London, UK, (1972).

18. Namburu, P. K., Das, D. K., Tanguturi, K. M., and Vajjha, R. S., "Numerical study of turbulent flow and heat transfer characteristics of nanofluids considering variable properties", International Journal of Thermal Sciences, 48 (2): 290-302 (2009).

19. Maxwell, J. C., "A Treastise on Electricity and Magnetism", 2nd ed. Ed., Oxford Univ. Press, Cambridge, USA, 440 (1881).

20. Einstein, A., "Eineneuebestimmung der molekuldimensionen", Annals of Physics, 324 (2): 289-306 (1906).

21. Brinkman, H. C., "The viscosity of concentrated suspensions and solutions", The Journal of Chemical Physics, 20 (4): 571 (1952).

22. Batchelor, G. K., "The effect of Brownian motion on the bulk stress in a suspension of spherical particles", Journal of Fluid Mechanics, 83 (1): 97-117 (1977).

23. Lide, D. R. and Frederikse, H. P. R., "CRC Handbook of Chemistry and Physics 19971998", Chemical Rubber Company, 78: (1997).

24. Yang, C., Wu, X., Zheng, Y., and Qiu, T., "Heat transfer performance assessment of hybrid nanofluids in a parallel channel under identical pumping power", Chemical Engineering Science, 168: 67-77 (2017).

25. A. Bejan, "Entropy Generation Minimization", CRC Press, Boca Raton, NY, (1996).

26. Cengel, Y. and Boles, M., "Thermodynamics: An Engineering Approach", 8th Edition. Ed., McGraw-Hill Education, (2014). 